\title{
The Challenge of Qualitative Generalisations in Communication Research
}

\author{
Bente Halkier
}

One of the questions by which we usually judge each others' research and our students' analytical skills is "what can we actually say using this piece of work?" What kinds of claims of generality are made, and how validly are these claims sustained? Valid generalisation is usually considered an important element of convincing research both in the qualitatively and the quantitatively oriented approaches to communication research (Jensen, 2002:266-68). Yet particularly among qualitatively oriented researchers, the possibility as well as the desirability of generalising beyond the particular context of data-production is sometimes questioned.

There is quite a body of literature describing the different analytical designs and models of inference and their consequences for generalisation at an epistemological level of theory of science (e.g., Blaikie, 1993; Danermark et al., 2002; Jensen, 2002; Ragin, 1987; Sayer, 1992). But it seems more difficult to find literature that describes concretely how to go about making valid generalisations at a practical methodological level, at least as regards research based on qualitative data. It appears to be implicitly assumed that we are able to appropriate and implement rather abstract, general and complex knowledge into well-functioning practical choices - something we would definitely question if it were assumed about any other group of text-users.

Thus, the purpose of this article is to contribute to the ongoing discussions within communication research by concretely exemplifying different strategies for making qualitative generalisations. This is attempted in two steps. First, the article discusses different principles and priorities in qualitative gen-

Department of Communication, Journalism and Computer Science, Roskilde University, Universitetsvej 1, DK-4000Roskilde,bha@ruc.dk eralisation. Second, the article describes three different concrete examples of generalisations in a research project on consumption and communication, explains how they were made and discusses why these categories can be understood as such types of generalisations.

\section{Qualitative Generalisation in General}

Comparing generalisations made from quantitative and qualitative data material, some important differences emerge. This is not to say that one way of producing data and generalising is better than another. Hopefully, the tendencies in communication research towards cross-fertilisation and convergence (Schrøder, 2001) will soon make these kinds of statements superfluous. What methods are used for data production should depend on what kind of question the researcher wishes to shed light upon and what theoretical approach is used. But having made these choices, what can be said on the basis of the two different types of data is quite different.

Respondents in quantitative communication studies, for example national television news audience studies, are selected by probability sampling to form a large sample in order to make the composition of the sample as similar as possible to that of the population (or at least to make the differences as small and predictable as possible). This way the patterns of television news watching can be statistically generalised back to the entire population from which the sample was drawn, because the sample is considered representative of the population (Hansen et al., 1998:239-42; Hellevik, 1984:76-89; Østbye et al., 1997:128-31). Thus, generalisation is constructed to go via the units of the sample to the population.

Informants in qualitative communication studies, for example ethnographic interviews about the in- 
ternal communication in an organisation, are chosen by selective sampling to form a small sample in order to make the composition of the sample reflect the most important analytical characteristics in relation to the research question. This depends, of course, on whether "maximum variation", "theoretical sampling", "best-case" or another model fits the research question. Thus, the socio-cultural patterns of the internal communication of the organisation can be analytically generalised to the theoretical categories in the field of internal organisational communication, because the sample results are considered to systematically conceptualise socio-cultural dynamics and relations (Blaikie, 1993:176-81; Johnson, 1990:27; Kvale, 1996:233-34; Neergaard, 2001:23-24). Hence, generalisation is constructed to go via the variables of the sample to the scientific categories.

The ability to make such analytical generalisations on the basis of qualitative data depends on a range of scientific choices, argumentations and performances. One important issue is, of course, all the concrete methodological choices and performances made as part of the overall analytical design of the research. Is the theoretical framework in accordance with the question and the research field? Are the operationalisations of theoretical concepts valid in relation to the research field? Is the sampling of informants or texts valid in relation to the theoretical framework, the intensive design and the research field? Do the data production and the interpretation and analysis of the data material show good and reflected workmanship? These choices, performances and their documentation - by making them explicit with argumentations for other communication researchers - are methodological pre-conditions for concrete attempts to establish analytical generalisations on the basis of qualitative inferences. This is what most methodology texts are about: trying to devise feasible and convincing principles for such workmanship.

Another important issue is the position in scientific theory taken by the researcher. Even though this article attempts, in the following sections, to show concretely how generalisations can be made, the level of theory of science in generalisations is not something than can be dispensed with. On the contrary, our basic understandings of the socio-cultural world and how to produce knowledge about it direct our practical research, and if researchers do not attempt to explicitly clarify such understandings in theory of science terms, there is always the risk of deficient analytical consistency or of working on the basis of non-analytical prejudices (Jen- sen, 2002:268; Knudsen, 1989). Moreover, the ways in which we attempt to make generalisations on the basis of qualitative data should reflect our positions regarding knowledge interests and knowledge production. Thus, theory of science positions are both very abstract constructions, but also have very concrete consequences.

An example of this is the use of language. This may seem trivial, but the words a researcher uses to describe a study are important. Some words signal very strongly to other researchers what kind of scientific theory, and hence epistemology, forms the basis of the generalisations. It is still not unusual to find that researchers and students who explicitly adhere to some variety of social constructivism can talk about data collection. Underlying this term, however, is the assumption that the socio-cultural data are out there, separate from the researcher, waiting to be picked up, which is at odds with one of the most important assumptions within social constructivism (Guba \& Lincoln, 1994). It is also not unusual to come across studies in which the overall design is labelled abductive (Blaikie, 1993:176-78), which indicates a flexible and revising relation between empirical categories and theoretical concepts. Nevertheless, such studies sometimes define and use some of the core theoretical concepts concretely and in a rather absolute manner, pretending to know exactly what should be looked for in the empirical field. This is in opposition to one of the intensions behind abductive inferences: To keep a systematically open mind towards several possible interpretations of categories and dynamics of the empirical field (Jensen, 2002:263-66) by, e.g., defining and using theoretical concepts in a more sensitive manner (for the distinction between absolute and sensitive concepts, see Blumer, 1954).

Finally, and getting closer to actual generalisations, it is also possible to read descriptions of qualitative data that lapse into numerical reports or mere pseudo-quantitative terms such as "how the majority of the informants think", thus using the language of another type of generalisation - the quantitative - that does not make analytical sense. It is, of course, quite a different matter if a combination of methodologies or a cross-over methodology is deliberately chosen, argued for and carried out, such as in Q-methodology (Schrøder \& Hansen, in press). Yet even in that case, the qualitative and the quantifying descriptions and arguments will usually be kept separate and then held together, but not mixed up.

Directly regarding generalisation, different theory of science positions tend to construct differ- 
ent goals for generalisation, depending on the knowledge interests expressed in the different approaches. Within realism, generalisation often involves an explanatory ambition (e.g., Danermark et al., 2002:96-98; Keat and Urry, 1987:27-36; Sayer, 1992:103-17). This is due to an assumption that, on a continuum from the very concrete to the very abstract, all categories are considered real. In this case, one of the goals of analytical generalisation is to explain very concrete events in communication and media using more abstract mechanisms and structures. Within some strands of social constructivism, however, generalisation involves a more interpretative and critical re-descriptive ambition (e.g. Åkerstrøm, 1999:13-15). Here assumptions come closer to not anticipating what is real, but to analysing how something becomes discursively constructed as real.

In the great middle range, insights from both theoretical approaches are combined. Communication researchers place themselves in various positions along a continuum between radical realism and radical constructivism. This, I will argue, describes much of the situation of so-called "normal" scientific praxis more adequately than does intense positioning in either camp. Perhaps this is because there is less contradiction between the positions at the epistemological and methodological levels than at the ontological level. Very few constructivists claim that material phenomena do not exist outside of our interpretations of them, while very few realists claim that material phenomena can be analysed without including interpretations. Within this group of combining approaches with, e.g., varying stress on deconstruction, the goal of generalisation be both interpretative and explanatory, where the explanatory part usually lacks strong causal mechanisms, but displays instead more open and contingent dynamics.

The three concrete types of analytical generalisation exemplified in the following main sections were all made within the context of such a combination of approaches. The research project concerns the ways in which consumers handle food risks and how they use media texts as part of this endeavour (Halkier, 2001a); the project is conceptualised within a theoretical framework that combines modern phenomenology and moderate social constructivism. I will argue - along with others (Alvesson \& Sköldberg, 2000) - that it is as legitimate and important to be able to analytically categorise the complexities of an empirical field as it is to uphold a stiff kind of theoretical cogency. The challenge is to reflect explicitly upon what consequences this may have for the concrete production of knowledge and its validity. Thus, researchers can use the three concrete types of analytical generalisation in slightly different ways, for example leaning more or less towards the social constructivist part of the continuum of theoretical positions. The three concrete ways of generalising are, of course, only examples and thus constitute suggestions about how to generalise analytically.

\section{Concrete Examples of Qualitative Generalisation}

The three different examples are all "established" generalisations in the sense that they have already been published, and they come from the same qualitative data material in one research project. It is my deliberate analytical intention to show how several different generalisations can emerge from one and the same project. Qualitative data are often so rich that they can be used for various interpretations that are not contradictory (hopefully, unless explicit change of perspective is intended), but rather complementary.

The research project analysed here concerns how consumers handle environmental food risks, with a focus on the use of social norms and public texts $^{1}$. In this sense, the research is related to the media and communication research tradition of qualitative user studies (e.g., Drotner, 1994; Morley \& Silverstone, 1991). As mentioned, the theoretical framework reflects both modern phenomenology and moderate social constructivism. On the one hand, there is a focus on the everyday life experiences with food risk that people produce, use and reproduce as consumers and media users through their socio-cultural practices in interaction with or in relation to important others (e.g., Goffman, 1959; Gronow \& Warde, 2001; Luckmann, 1989; Thompson, 1995). On the other hand, there is a focus on the food and risk interpretations of people as consumers and media users in an interplay between their situational negotiations and fixations of definitions, and the mediated institutional framings of meaning (e.g., Garfinkel, 1967; Goffman, 1974; Laclau, 1996; Potter \& Whetherell, 1987).

The empirical data material consists of a combination of data from focus groups (Morgan, 1997) with parents of small children discussing food and risk-handling, and a sample of different kinds of public texts about food and risk. The participants in the focus groups were sampled according to a combination of ethnographic network-snowballing (Johnson, 1990) and variation regarding education 
and place of living. The public texts were sampled as types in terms of the kinds of texts the parents in the focus groups explicitly mentioned using in their understandings of food risks ${ }^{2}$. The data material was analysed via systematic qualitative coding and categorising (Coffey \& Atkinson, 1996), metaphors and domain interpretation (Hall, 1997; Spradley, 1979) as well as conversation and discourse analysis (Antaki, 1994; Potter, 1996). The expressions of the parents' risk interpretations and risk-handlings were interpreted as happening in the interplay between their individual narratives, the social and communicative dynamics of the groups, and the larger discursive repertoires in society.

\section{Ideal Types}

The first type of analytical generalisation is probably also the most widely used one. Examples of ideal types representing generalisations of primary qualitative data or conceptual generalisations over both primary and secondary data are well known to everyone in communication and media research. There are the typical media-user typologies, based on qualitative data materials, categorising media users as, for example, super-users, users and non-users (e.g., Stald, 1998) or classifying media users according to their lifestyles (e.g., Dahl, 1995). And there are also many analytical concepts that reflect ideal type categorisations of aspects of media use (e.g., Silverstone, 1994) and text reception (e.g., Schrøder, 2000). Major parts of ideal type qualitative generalisations in media and communication research are constructed as segments, types of user practices and types of interpretive repertoires.

The notion of an ideal type comes from one of the founding fathers of sociology, Max Weber, who defined it as a one-sidedly focused synthesis of diffuse and discrete empirical phenomena into a unified abstract analytical construct, which will never be discovered in this specific form (Weber, 1949:90). The basic process in constructing ideal types is to condense the codings, categories and interpretations of the data material into a limited number of relevant descriptions that one-sidedly underline particular characteristics at the cost of others. Ideal types are meant to reflect their name in the sense that the types cannot be found or categorised (depending on your theoretical position) directly in their pure form in the empirical field. Thus, making an ideal type entails considerable complexity reduction. The challenge is not to oversimplify such a reduction, which is a necessary part of all data treatment and attempts at generalisation.
The concrete example from my research project is a typology of three ideal types of risk-handling in food consumption. In other words, these are ideal types of user practices. The types are called worried risk-handling, irritated risk-handling and pragmatic risk-handling (Halkier, 2001c).

In worried risk-handling, food is something that is talked about, and risk is considered an important family issue. Debates in the media are followed, information on risk issues is actively sought, and the question of how one should respond is subject to negotiation within the social network. Consumers attempt to buy and use food stuffs that they typify as less risky, as this woman explains: "No, no...but a better kind of foodstuff in the sense that...well, we can't know, can we, but it's probably because we hope that, there ARE not so many leftovers of all sorts of strange stuff that we don't know about how they will react in our body, right? That's why we are ready to pay a bit more for it, right?" There is a tendency to see oneself, as a consumer, as capable of agency in society, as making a difference in food security and quality through one's practices. Trust in relation to handling food risks is expressed both as abstract institutional relations, such as state-controlled labelling schemes, but also as close-knit personal relations, such as getting apples from your neighbour.

In irritated risk-handling, food is something that is enjoyed, and risk in relation to food is understood as something that threatens other everyday life relations around food. Thus, risk is primarily associated with the amounts of risk communication in the media, that which "enters" family life via television and newspapers. Irritated risk-handling entails considerable frustration and shifting practices at different times, often according to how mediated discourses are experienced or because other everyday concerns are prioritised. A diffuse lack of trust in all other societal actors is expressed, and consumers do not see themselves as carrying any agency in society in relation to food issues. This is expressed by one of the men: "But I am also tired of them [i.e. media, authors note] in the sense that...they take up something, right, and then actually, I sit and get all excited about it and say that it's bloody well too bad...but my possibilities to do ANYTHING about it, they are not really there... are they? So... the fish doesn't get better from them making such a show, right? I've just had yet another problem thrown in my face, right?"

In pragmatic risk-handling, food is not talked about, and risk in relation to food is understood as yet another daily life problem for which some prac- 
tical solutions must be found. Thus, particular choices and practices are settled and turned into practical routines so it is not necessary to reflect upon the problems every time consumers shop, cook, eat and watch television. This is expressed in the following quote: "I also think about things such as fruit and the like, you can't assess when they say it's not sprayed, but I don't believe very much in that, you know. I think it's all sprayed to some degree, you know. But you know, you can't do anything else but buy it and wash it and then...eat it." Here, trust in relation to risk-handling is varied just as for worried risk-handling.

These three ideal types of risk-handling with regard to food are each representations of consumers and media users that have been pushed to the extremes. They were constructed in four steps. First, a round of basic open coding and a round of relational categorising, using everyday life analytical categories, were made of the whole focus group data material (Coffey \& Atkinson, 1996:26-45). Second, the first contours of differences in ways of handling risk emerged from the categorising, and I categorised patterns in similarities and differences in risk-handling practices and interpretations, while still "combing" the entire material in order to also look for systematicity against the emerging patterns of similarity and difference. Third, I concentrated on the now apparent different types of practices and began to aim for a "connected" form of practice for each using thematic coding, i.e., a type of risk-handling that one-sidedly underlined particular characteristics and that was distinctively different from the others. Examples of the characteristics cultivated were how risk is socio-culturally associated, how media texts are used in relation to risk-handling, and which particular types of practical appropriations are carried out. Finally, theoretical conceptualisations of the three ideal types were also applied, placing the different types of risk-handling in relation to discussions on the contested space of the body in modern societies (e.g., Foucault, 1978).

Furthermore, we can use this example of ideal type generalisation to argue that ideal types can be used irrespective of where the researcher places herself on a continuum between critical realism and social constructivism. If the researcher's orientation is more towards the realist side, perhaps the focus will be more on trying to explain which socio-cultural structures form the differences in risk-handling experiences. However, if the researcher's orientation is more towards the constructivist side, perhaps the focus will be on underlining how con- sumers can occupy the different positions of the types in different socio-cultural contexts.

\section{Variables}

Using the term variable may seem misplaced to some researchers working with qualitative methods as it comes out of quantitative terminology. However, the term is used here to reflect how qualitative generalisation in general goes via the variables. But the term is also used in the heading as shorthand for the single elements of social and cultural categories and dynamics of studies. In this way, this type of generalisation usually "zooms in" on particular single aspects of the results of a study as parts of the qualitative generalisation.

Single variable generalisation plays an important role in, for example, comparative studies and case study research, where it is important to explicate rather precisely what is being compared if the ambition is to say something more general than telling e.g. a number of localised case stories. One could, in principle, attempt such a task by constructing ideal types as well, but case studies and comparative studies often involve such large data material that, in order to keep up systematics, each variable is first categorised and analysed individually. At the level of single aspects of the data material, the researcher decides whether the patterns of this single aspect display characteristics sufficiently identical to be formally ascribed to one category (Ragin, 1987).

However, this way of looking at even single aspects of empirical patterns as things that can be ascribed decidedly to one category does not tally well with some approaches to qualitative research in which the complexity of patterns and the cross-categorisations of patterns are often underlined (Coffey \& Atkinson, 1996). Some would perhaps suggest grounded theory methods (e.g., Strauss \& Corbin, 1990) to include such complexities, as this approach appears to be focused on single variables via elaborate coding procedures combined with a sensitivity to context via its stress on concepts to be grounded in the empirical field. But grounded theory tends to work from an inductivist assumption, thus legitimising a scientific theoretical position wherein researchers can enter a field without theoretical (or socio-cultural) presuppositions (Alvesson \& Sköldberg, 2000:32). Furthermore, the elaborate coding procedures seem rather mechanistic, commonsensical and in the end decontextualising (Coffey \& Atkinson, 1996:48; Jensen, 2002:248). 
Instead, I will suggest that supplementing qualitative systematic coding and thematic categorisation with a theoretical framework that can conceptualise the complexities of the context of one's variables could be one way of avoiding formalistic ways of using variables in qualitative generalisations. Working in an abductive manner, this would be part of the processes of re-describing and re-contextualising single aspects of data (Danermark et al., 2002:10910). Thus, it is important to see the single aspects of data patterns (the variables) as always being in configuration with other dynamics of the context. In a way, this can be described as making a Norbert Elias "twist" on variable generalisation. Elias uses the term "figuration" to transcend the views that see the individual level of analysis as something separate from the societal level (Elias, 1978b:12833 ); by figuration he meant the patterns of relationships in socio-cultural processes. Thus, seeing single variables in configuration with relevant dynamics of the soci-cultural context constitutes making variable generalisation relational.

The concrete example from my research project can be seen as a generalisation of four configurations of the single aspect of ambivalence in consumers' handling of risk communication (Halkier, 2001a).

"Ambivalence as tension" is the first configuration of the category. Here consumers experience ambivalence, in relation to their use of media texts concerning food risk-handling, as conflicts resulting in tensions in everyday life. Consumers find it difficult to avoid knowledge about various risks due to the extent of information and debate in the media. This problematisation of food in the media is experienced as spoiling the pleasurable and important things about food in the family, such as enjoying the taste of meals and arranging meals to strengthen the family feeling, because forced reflections on food easily come into conflict with the pleasures. Here, the relations around ambivalence seem to accord with the tension between desire and control of bodily practices, conceptualised in the literature that relates body and culture to general historical tendencies in modernity (Elias, 1978a:245-63; Foucault, 1978:139-45).

"Ambivalence as legitimate" denotes consumers' relations with ambivalence in using media texts in risk-handling, where ambivalence is interpreted as an acceptable aspect of risk-handling. Contradictions between, for example, general recommendations of mediated discursive repertoires on food risks and specific deficiencies in space of action in everyday life are interpreted as negative. But these are things consumers have to live with, because such ambivalence is a basic condition of being a food consumer in a medialised society. Hence, ambivalence arises from the contingency of social life and consumers can differentiate themselves discursively from having a personal problem. The consumer accounts around this have a tendency to be characterised by facticity, and a relational interpretation of accounts constructing facticist claims could be to see them as attempts at establishing the social legitimacy of one's own practices (Potter, 1996:12224).

"Ambivalence as normal" categorises the consumer experiences with ambivalence in using media texts in risk-handling as normal, where ambivalence is being incorporated into everyday practices without necessarily producing much tension or resulting in attempts at legitimation. Thus, ambivalence is made a normal feature of practices and becomes built into the continuous story of oneself as a consumer, and mediated discursive repertoires are only tacitly drawn upon. Here, it is possible to fit, for example, tinned conventional fast food into a food style of fresh organic food. This process can be seen as a parallel to Georg Simmel's argument about fashion. He describes a process in everyday life whereby subjective individual changes in styles of practices can be incorporated via bricolage that is socially stylised, that is the "deviations" are worked into a new practical display or discursive narrative by drawing upon a recognisable social frame (Simmel, 1991:69).

“Avoiding ambivalence?" describes the consumer experience wherein avoidance of the very experience of ambivalence is attempted. Here consumers routinise their risk-handling practices, and since routines work on tacit knowledge and bodily remembrance, the potentially forced reflexivity in appropriation of mediated discursive repertoires on food risk, being in conflict with other food relations, can be escaped. Such processes illustrate the debate about the individual being ascribed with more moral responsibility in a medialised society, and about whether this constitutes an opportunity or a problem (Thompson, 1995:225-34).

The four configurations of the variable ambivalence were constructed later than the three ideal types. Hence, all the basic coding and categorising was already done. In fact, I began to "zoom in" on the single aspect of ambivalence, because the ideal types of risk-handling had been criticised for not conceptualising contradictions, polyvalence, shifts and liminality. Furthermore, an analysis comparing the dominating discursive repertoires in the focus group data material and the other set of data material - the public texts on food risks - pointed to am- 
bivalence as an important characteristic of consumers' constructions of their own role in risk-handling. Thus, a focussed thematic coding of the data material around ambivalence was carried out, partly also inspired by domain interpretation (Coffey \& Atkinson, 1996:92-99). Then these patterns of consumer experiences with ambivalence were conceptualised by associating them with concepts for context-relevant socio-cultural relations.

\section{Narratives}

This kind of qualitative generalisation has come forward as researchers inspired by different versions of social constructivism and post-structuralism have problematised some of the ways of doing ideal type generalisation and variable generalisation for producing representations that exaggerate the stability of phenomena and relations. The argumentation unfolds as follows: if researchers assume, and are able to demonstrate empirically, that phenomena and relations are formed by people's practical use of language in shifting and complex socio-cultural contexts, then this potential plurality and non-finality should be reflected better in our generalisations. This is one of the basic premises of, for example, the different types of discourse analysis (e.g., Jørgensen \& Phillips, 1999; Laclau, 1996; Potter \& Whetherell, 1987).

Practical methodological suggestions for producing different generalisations have included constructing positions or positionings (Jensen, 1998), talking about possibilities instead of descriptions (Peräkylä, 1997), and making representations as voices (Stern, 1998). There are two common characteristics of these suggestions. First, they try to combine the complexity and non-finality of empirical data material with analytical systematics, which orders patterns in a story-like way rather than a thing-like way (Tseëlon, 1992). This characteristic is the reason for labelling such generalisations as narrative. Second, they take into account the symbolic power of scientific representations and they counterbalance this power of the researchers; thus expressions of the participating subjects are represented fairly directly. This is not done as a claim to authenticity, but as a recognition of the polyphony involved in the first-order constructs of the sociocultural processes in question and thus in creating second-order constructs (Alvesson \& Sköldberg, 2000:258-59; Blaikie, 1993:179-81).

The concrete example of narrative generalisations from my research project is the four social norms that "result" from consumers' norm negotia- tion about risk-handling in food, although the study produced many more (Halkier, 2001b). This generalisation can be seen as an example of the generalised categories consisting of positions that actors can occupy to various degrees in different contexts. It would take up too much space to illustrate all four norms with the necessary lengthy quotes of discussions, so only one of the norms will be illustrated, and the other three will merely be mentioned.

The examples of norms for handling food risks on which consumers established consensus in their negotiations with one another are the following:

- Personally known products are best

- You should buy Danish

- Keep your anxiety over dirt in check

- Cutting corners is okay in a busy everyday life

The last norm - or position that consumers and media-users can take discursively - is being negotiated towards a consensus in the following quote:

Jan: "The chickens we had tonight, actually they are Easter food, right? But it's often difficult. In reality, it is limited to a couple of months where you can get chickens...if you should follow the seasons, right?" [Marie: Yeah...]

Mette: "But that's also the ideal thought. You know, that's when you talk about it and think, oh but what is it I would like to do. Now and then you remember that this is what you prefer to do - and then there are the days when you fuck-all just have to get the children from daycare and shop and you are off at seven o'clock, right? Then it's roast pork and... [Jan: "Oh, you mean Monday to Friday?"]... and French fries or such things."

Marie: "You know, if the children can choose what we are having today, we have roasted something with potatoes and gravy. And then you know there's peace and quiet! Everyone eats and is happy."

Mette: "This is what...at least I think it's important to allow yourself to say, but that's the way it is then, right?" [Marie: "Mmm."]

The positions that each norm represents were constructed after the basic work of coding and categorisation was carried out, building on this work, like the example on variable generalisation around the variable ambivalence. For producing the norm positions, the following step was taken. I combined a 
focused categorisation and conceptualisation by combining a number of different categories for dealing with norms, such as conventionality, facticity and reflexivity (Mortensen, 1992), with an analysis of handling of consensus and conflicts around these norms using tools from discourse psychology, such as interest management and category entitlement (Potter, 1996:112-18).

\section{Conclusion}

It has been the purpose of the present article to contribute to the methodological debate in communication research about generalisation on the basis of qualitative data. While much has been written about qualitative or analytical generalisation at a more abstract theory of sciencelevel, little has been written about the practical, methodological "how-to-do-it" aspects. Hence, the article presents and explains in detail three different types of analytical generalisation and shows how these generalisations were constructed on the basis of qualitative data material. This focus on the practical methodological level is not to say that scientific theoretical discussions related to qualitative generalisation can be dispensed with. On the contrary, the point is that there is (or ought to be) an intimate relation between the researcher's scientific theoretical position and the practical methodological design of the entire research process, including the making of generalisations. Theory of science positions are very abstract constructions and they have very concrete consequences. Thus, the article discusses, for each of the three presented types of qualitative generalisation, how the generalisation could be used, depending on where the researcher positions herself on the continuum from critical realism to social constructivism.

The article has presented three different ways of making analytical generalisations: Ideal types, variables in configuration, and narratives. Ideal types are seen as condensed syntheses of the complexities of, e.g., a whole communication context or a connection of several communication dynamics, where particular characteristics are underlined at the cost of others. Variables in configuration are seen as focussing on one aspect of a communication issue or context at a time, but also as seeing this single aspect in relation to relevant socio-cultural dynamics. Narratives are seen as orderings of patterns of communication dynamics in story-like ways, reflecting the potential plurality and non-finality of the generalisations. The three different kinds of generalisation are exemplified with concrete established generalisations from a research project about how consumers use media texts in their handling of food risks in everyday life.

An important discussion, which is not touched upon explicitly in the article, is what such generalisations can be used for. In media and communication research, such generalisations can be used for mapping or representing socio-cultural fields of communication, for clarifying theoretical concepts at all levels of applicability, and for interpreting or explaining communication phenomena in dynamic and detailed ways. Thus, analytical generalisations can also be used by other researchers to build upon and revise in their own analytical designs and studies. Ideal types, variables in configuration and narratives, unsurprisingly, cannot be used to say anything about the frequency and distribution of particular communication patterns in communication user populations. And if the research producing the specific kind of analytical generalisation is designed to be dominantly social constructivist, the researcher would probably argue that the generalisations should not be seen as stable categories with which to sort out and distinguish between, for example, individual media users.

However, the problem is that outside the world of research, journalists, administrators, business people, campaign makers, and political organisations have a tendency to mould the original complex and not necessarily stable analytical generalisations into heavy-handed simplified results such as new segments or so-called truths about communication user populations in order to suit their own interests. Thus, it is indeed a challenge for us as researchers to guide our own communication of complex analytical generalisations, as well as other societal actors' potential use of them, such that these generalisations are intelligible, but not over-simplified. 


\section{Notes}

1. The project was entitled, "The Risks of Consumption: Environmental Norms and Consumer Practices". It was financed by the The Strategical Environmenal Research Programme, and it was carried out under the auspices of Centre for Social Scientific Environmental Research in Denmark (CeSam) See Halkier, 2000, Halkier, 2001a - c for details.

2. The four types are information leaflets available in supermarkets, particular thematic television shows, television news, and the actual food stuff consumer goods themselves, including their packaging.

\section{References}

Alvesson, M \& Sköldberg, K (2000) Reflexive Methodology. New Vistas for Qualitative Research. London: Sage.

Antaki C (1994) Explaining and Arguing. The Social Organization of Accounts. London: Sage.

Blaikie N (1993) Approaches to Social Enquiry. Cambridge: Polity.

Blumer H (1954) What is Wrong with Social Theory? American Sociological Review. Vol. 19 (1).

Coffey A \& Atkinson P (1996) Making Sense of Qualitative Data. Complementary Research Strategies. London: Sage.

Dahl H (1995) Nogle Erfaringer med at Operationalisere Bourdiue. Mediekultur. No. 24.

Danermark, B; Ekström, M; Jakobsen, L \& Karlsson J C (2002) Explaining Society. Critical Realism in the Social Sciences. London: Routledge.

Drotner, K (1994) Ethnographic Enigmas: 'The Everyday' in Recent Media Studies. Cultrual Studies. Vol. 8 (2).

Elis, N (1978a) What is Sociology? London: Hutchinson.

Elias, N (1978b) The Civilizing Process 1: The History of Manners. Oxford: Blackwell.

Foucault, M (1978) The History of Sexuality. Vol. 1. Harmondsworth: Penguin Books.

Garfinkel, H (1967) Studies in Ethnomethodology. New Jersey: Prentice Hall Inc.

Goffman, E (1974) Frame Analysis. An Essay on the Oganization of Experience. Cambridge Massachusetts: Harvard University Press.

Goffman, E (1959) The Presentation of Self in Everyday Life. New York: Anchor Books.

Gronow, J \& Warde, A (2001) Ordinary Consumption. London: Routledge.

Guba, E B \& Lincoln, Y S (1994) Competing Paradigms in Qualitative Research. In Handbook of Qualitative Research (ed. N K Denzin \& Y S Lincoln). London.

Halkier, B (2001a) Consuming Ambivalences. Consumer Handling of Environmentally Related Risks in Food. Journal of Consumer Culture. Vol. 1 (2).
Halkier, B (2001b) Consuming Risk. Environmentality and Consumers' Handling of Risk in Food Consumption. Zhurnal Sotsiologii i Sotsialnoi Antropologii (English version of the Russian journal).

Halkier, B (2001c) Risk and Food: Environmental Concerns and Consumer Practices. International Journal of Food Technology and Science.Vol. 36, pp. 801-12.

Hall, S (1997) The Work of Representation. In: Representation. Cultural Representations and Signifying Practices (Ed. S Hall). London: Sage.

Hansen, A; Cottle, S; Negrine, R \& Newbold, C (1998) Mass Communication Research Methods. London: Macmillan.

Hellevik O (1984) Forskningsmetode $i$ Sosiologi og Statsvitenskap. Oslo: Universitetsforlaget.

Jensen I (1998) Interkulturel Kommunikation i Komplekse Samfund. Frederiksberg: Roskilde Universitets Forlag.

Jensen K B (2002) A Handbook of Media and Communication Research. London: Routledge.

Johnson J (1990) Selecting Ethnographic Informants. London: Sage.

Jørgensen M W og Phillips L (1999) Diskursanalyse som Teori og Metode. Frederiksberg: Samfundslitteratur.

Keat, R \& Urry, J (1987) Social Theory as Science. London: Routledge \& Kegan Paul.

Knudsen, A (1989) Når Verden er Anderledes. Korsikanske Utroligheder. In Feltarbejde. Oplevelse og Metode $i$ Etnografien (ed. K Hastup og K Ramsløv). København: Akademisk Forlag.

Kvale, S (1996) Inter Views. An Introduction to Qualitative Research Interviewing. London: Sage.

Laclau, E (1996) Deconstruction, Pragmatism, Hegemony. In: Deconstruction and Pragmatism (Ed. S Critchley et al) London: Routledge.

Luckmann, T (1989) On Meaning in Everyday Life and in Sociology. Current Sociology. Vol. 37 (1).

Morgan, D L (1997) Focus Groups as Qualitative Research. London: Sage.

Morley, D \& Silverstone, R (1991) Communication and Context: Ethnographic Perspectives on the Media Audience. In A Handbook of Qualitative Methodologies for Mass Communication Research (Ed. K B Jensen \& N W Jankowski). London: Routledge.

Mortensen, N (1992) Future Norms. In From Voters to Participants (Ed. P. Gundelach \& K. Siune). Politica, Århus.

Neergaard, H (2001) Udvalgelse af Cases $i$ Kvalitative Undersøgelser. Frederiksberg: Samfundslitteratur.

Peräkylä, A (1997) Reliability and Validity in Research Based on Transcripts. In Qualitative Research. Theory, Method and Practice (Ed. D. Silverman). London: Sage.

Potter, J (1996) Representing Reality. Discourse, Rhetoric and Social Construction. London: Sage.

Potter, J \& Whetherell M (1987) Discourse and Social Psychology. Beyond Attitudes and Behaviour. London: Sage. 
Ragin, C. (1987) The Comparative Method: Moving be yond Qualitative and Quantitative Strategies. University of California Press.

Sayer, A (1992) Method in Social Science. A Realist Approach. London: Routledge.

Schrøder, K (2001) Beyond the Pioneer Days! - Where is Reception Research Going? Cross-fertilization of Paradigms: A Synthesizing Approach to Qualitative Audience Research. Nordicom Review. Vol. 22 (1).

Schrøder, K (2000) Making Sense of Audience Discourses. Towards a Multidimensional Model of Mass Media Reception. European Journal of Cultural Studies. Vol. 3 (2).

Schrøder, K \& Hansen, S E (in press) Beyond Duality. Danes' Views on Denmark and the European Union 2001. In R. Roby (ed.): The Changing Face of European Identity: An Eight-Nation Q Study of (Supra) National Attachments. Lynne Riener Publishers.

Silverstone, R (1994) Television and Everyday Life. Routledge, London.

Simmel, G (1991) The Problem of Style. Theory, Culture and Society. Vol. 8 (3).

Spradley, J P (1979) The Ethnographic Interview. Holt, Rinehart and Winston, Fort Worth.
Stald, G (1998) Living with Computers. Young Danes' Uses of and Thoughts on the Uses of Computers. Sekvens. Copenhagen University: Department of Film and Media Studies.

Stern, B (1998) Narratological Analysis of Consumer Voices in Postmodern Research Accounts. In Representing Consumers. Voices, Views and Visions (Ed. B Stern). London: Routledge.

Strauss, A \& Corbin J (1990) Basics of Qualitative Research: Grounded Theory Procedures. London: Sage.

Thompson, J B (1995) The Media and Modernity. A Social Theory of the Media. Cambridge: Polity.

Tseëlon, E (1992) Is the Presented Self Sincere? Goffman, Impression Management and the Postmodern Self. Theory, Culture and Society. Vol. 9.

Weber, M (1949). The Methodology of the Social Sciences. Glencoe: The Free Press.

Østbye, H; Helland, K; Knapskog, K; \& Hillesund, T (1997) Metodebok for Mediefag. Bergen: Fagbokforlaget.

Åkerstrøm Andersen, N (1999) Diskursive Analysestrategier. Nyt fra Samfundsvidenskaberne, København: Handelshøjskolen. 